\title{
ENSINO DE AGROECOLOGIA E EDUCAÇÃO AMBIENTAL: UMA ANÁLISE A PARTIR DA CONSTITUIÇÃO DE 1988 E DA CRÍTICA DO PARADIGMA ANTROPOCENTRICO'
}

\author{
TEACHING OF AGROECOLOGY AND ENVIRONMENTAL EDUCATION: AN ANALYSIS \\ BASED ON THE 1988 CONSTITUTION AND THE CRITIQUE OF THE \\ ANTHROPOCENTRIC PARADIGMA
}

\begin{abstract}
Maria Creusa de Araújo Borges
Professora do Mestrado e do Doutorado em Direito e Coordenadora do Programa de Pós-Graduação em Ciências Jurídicas da Universidade Federal da Paraíba. Líder do Grupo de Pesquisa Educação, Direito e Sociedade (CNPq).

E-mail: mcaborges@gmail.com

William Bispo de Melo

Mestrando em Direito Econômico no Programa de Pós-Graduação em Ciências Jurídicas da Universidade Federal da Paraíba, Brasil. E-mail: williambispo11@gmail.com.
\end{abstract}

Recebido em: 04/07/2019

Aprovado em: 13/12/2019

RESUMO: O artigo problematiza o ensino de agroecologia na perspectiva da educação e da conscientização ambiental com aporte na Constituição Federal de 1988 (CF/88), especificamente no art. 225. Assume, como ponto de partida, a crítica do paradigma antropocêntrico, o qual, entre outros aspectos, trata a natureza como 'recurso a ser explorado'. Na primeira parte, se busca uma contextualização e análise do conceito de agroecologia e a caracterização dos aspectos socioambientais. Em seguida, se realiza uma análise da normativa referente à agroecologia, com aporte na CF/88, no Decreto Federal $n^{\circ}$ 7.794/2012, que institui a Política Nacional de Agroecologia e Produção Orgânica, e na Lei Federal nº 10.831/2003, que dispõe sobre a agricultura orgânica. Na terceira parte, se discute o ensino de agroecologia, inserido numa concepção de educação e conscientização ambiental, a partir da abordagem da ecologia de saberes como perspectiva epistemológica, e da crítica do paradigma antropocêntrico, cujas características estão presentes no texto constitucional e cuja superação é necessária para a concretização do disposto no art. $225, \S 1^{\circ}$, VI, da CF/88.

Palavras-chave: Agroecologia. Educação Ambiental. Constituição Federal de 1988. Ecologia de Saberes. Paradigma Antropocêntrico.

ABSTRACT: The article problematizes the teaching of agroecology in the perspective of education and environmental awareness with contribution in the Federal Constitution of 1988 (CF / 88), explained in art. 225. It assumes, as a starting point, the critique of the anthropocentric paradigm, which, among other aspects, treats nature as a 'resource to be explored'. In the first part, the goal contextualization and analysis of the concept of agroecology and the characterization of the socioenvironmental aspects. Giving sequence is portrayed about an analysis of the regulations

${ }^{1}$ Pesquisa financiada pela Coordenação de Aperfeiçoamento do Pessoal de Ensino Superior (CAPES).

Revista de Direito Brasileira | Florianópolis, SC | v. 24 | n. 9 | p.365-377 | Set./Dez. 2019 
related to agroecology, with contribution in CF / 88, Federal Decree No. 7.794 / 2012, which establishes the National Policy on Agroecology and Organic Production, and Federal Law 10.831 / 2003, which provides on organic agriculture. The third part is addressed the teaching of agroecology, inserted in a conception of education and environmental awareness, from the approach of the ecology of knowledge as an epistemological perspective, and of the criticism of the anthropocentric paradigm, whose characteristics are present in the constitutional text and whose overcoming is necessary for the implementation of the provisions of art. $225, \S 1^{\circ}, \mathrm{VI}$, of CF / 88.

Keywords: Agroecology. Environmental education. Federal Constitution of 1988. Ecology of Knowledge. Anthropocentric Paradigm.

SUMÁRIO: Introdução; 1 Uma contextualização da agroecologia; 2 Aspectos normativos sobre a agroecologia; 3 Ensino de agroecologia: parâmetros teóricos e epistemológicos; Conclusão; Referências.

\section{INTRODUÇÃO}

O ensino de agroecologia se insere no texto constitucional de 1988 , art. $225, \S 1^{\circ}$, VI, no tópico referente à necessidade de uma educação e conscientização ambientais para fins de concretizar o direito de todos ao meio ambiente ecologicamente equilibrado. Para concretização dessa finalidade, o poder público, dentro dos parâmetros constitucionais, deve promover a educação ambiental em todos os níveis de ensino e a conscientização pública sobre a necessidade de preservação do meio ambiente.

Nesse cenário, é problematizada a questão do paradigma antropocêntrico como norteador de dispositivos constitucionais concernentes à matéria do meio ambiente e à necessária preservação, sobretudo, no que diz respeito à função socioambiental da propriedade rural, normatizada no art. 186 da Constituição Federal de 1988 (CF/88), cujos requisitos reportam a natureza como um 'recurso a ser explorado', gerando impactos numa concepção de educação ambiental centrada no ser humano como um sujeito epistêmico e que compreende a natureza como um objeto. A partir da crítica desse paradigma, e no quadro da $\mathrm{CF} / 88$, sobretudo do projeto a ser instituído com fundamento no art. 225, é problematizada uma concepção de educação ambiental e de ensino de agroecologia a partir da crítica do paradigma antropocêntrico, propondo sua superação na perspectiva da ecologia de saberes, uma abordagem centrada na interculturalidade, na produção e na socialização dos conhecimentos e saberes produzidos por diferentes povos (SANTOS, 2010).

Com fundamento nesse parâmetro, é pensado o ensino de agroecologia na educação básica (ensino fundamental e médio), buscando, em apertada síntese, explicar a relação da "tríplice aliança" entre indústrias, bancos e latifundiários e o modo de produzir baseado em monoculturas, com o uso de agrotóxicos em larga escala, produção de commodities no agronegócio. Conceitos que implicam a necessidade de instrução e conscientização sobre a produção agroecológica e sua relação com a preservação ambiental, finalidade da normativa constitucional do art. 225.

Considera-se o Brasil o maior consumidor mundial de agrotóxicos. De 2008 até o presente momento (2018), totalizando 10 (dez) anos dessa "supremacia", que acarreta diversos problemas socioambientais, seja para a natureza (flora e fauna contaminadas), seja para os trabalhadores e consumidores intoxicados em maior ou menor grau (LONDRES, 2011, p. 19).

A promoção, nesse âmbito, do conhecimento sobre a agroecologia, com fundamento numa concepção epistemológica da ecologia de saberes e com aporte na CF/88, art. 225, contribui para a proteção da saúde humana (consumidores e trabalhadores rurais), mas, sobretudo, favorece o equilíbrio ecológico ambiental na perspectiva do direito da natureza. 
São apresentados os marcos legais relevantes sobre a agroecologia, tais como a CF/88, o Decreto Federal n. 7.794/012, que institui a Política Nacional de Agroecologia e Produção Orgânica e a Lei Federal n.10.831/2003, que dispõe sobre a agricultura orgânica e dá outras providências, com o fito de fundamentar a legalidade da agroecologia e a urgência do seu ensino na perspectiva da conscientização e preservação ambiental.

Por fim, na terceira parte, o artigo se propõe a apresentar uma perspectiva para o ensino de agroecologia, com aporte no marco teórico e epistemológico da abordagem da ecologia de saberes (SANTOS, 2010), fundamentada em reflexões sobre os diversos saberes legítimos, além do científico, que podem servir de base para a educação e o ensino, tais como os saberes das comunidades tradicionais, quilombolas, indígenas vinculados a uma prática de preservação ambiental. Nessa senda, se discute a matéria a partir da crítica da visão antropocêntrica que, ainda, tem norteado a normativa referente à proteção ambiental.

\section{UMA CONTEXTUALIZAÇÃO DA AGROECOLOGIA}

Primeiramente, a agroecologia é definida como um sistema produtivo específico e diferenciado do sistema vigente dominante, fundamentado em práticas alternativas de produção em consonância com uma concepção de desenvolvimento sustentável. Nesses termos, no Dicionário da Terra, organizado por Motta (2005, p.27-28), a agroecologia constitui:

um dos ramos da produção agrícola, tendo elementos específicos que a determinam como alternativa produtiva ao modelo agrícola vigente no século XX. Tem conexões com a agricultura orgânica, agricultura familiar, modos familiares de tradicionais de produzir, agroflorestas e, é claro, com o desenvolvimento sustentável. (...) É um sistema produtivo que prioriza os recursos internos dos ecossistemas, através da reciclagem, e o sinergismo entre os seus componentes biológicos para combater pragas e outros problemas ocasionados pelo desequilíbrio ecossistêmico local (controle biológico). Além disso, proporciona o resgate e a renovação permanente da fertilidade do solo e, ainda, a manutenção da produtividade e a proteção das culturas. Outro componente imprescindível ao funcionamento de uma unidade agroecológica é o fator energético, pois conjuntamente à redução ou à eliminação dos insumos químicos e agrotóxicos - a serem substituídos pelo aproveitamento de resíduos da unidade produtiva -, está a maior independência do combustível fóssil.

Como se observa, a agroecologia se constitui como uma disciplina científica com aporte na teoria e prática ecológicas para produzir. Baseia-se em críticas a um modo de produção tradicional, fundamentado em latifúndio que produz no regime de plantation, via monocultura, para a produção de commodities (culturas extensivas de exportação), tais como cana-de-açúcar, café, algodão, cacau e a pecuária extensiva, utilizando tecnologia química (agrotóxicos, transgênicos) e tecnologia mecânica em uma dinâmica de reprimarização da economia e de comoditização da agricultura (VITTI, SOUZA, 2012; SOUZA, CABERO DIEGUES, 2012).

O Dicionário da Terra expõe, detalhadamente, o modo de produção da agroecologia, o qual valoriza os saberes dos camponeses, na perspectiva da ecologia de saberes como defendida na abordagem de Santos (2010, p. 138). Dessa forma, Motta (2005, p.28) esclarece:

os elementos técnicos centrais da estratégia agroecológica referem-se à conservação e à regeneração dos recursos naturais (solo, água, fauna, flora nativas); aos manejos dos recursos produtivos adequados às diversidades físicas e climáticas (locais/regionais), à reciclagem dos nutrientes e matéria orgânica (biomassa animal e vegetal) e reutilização de recursos e nutrientes internos e externos à propriedade e, ainda, à regulação biótica (proteção de cultivos e saúde 
animal); à implementação de elementos técnicos de conservação e manejo adequados às necessidades locais e ao contexto agroecológico e socioeconômico, considerando-se o nível de implementação nos termos da microrregião, bacia hidrográfica, unidade produtiva ou sistema de cultivo.

A agroecologia, praticada em produção familiar, se contrapõe à concepção de produção do agronegócio. Como um paradigma produtivo sustentável, a agroecologia, conforme Dossiê da ABRASCO (2015), é uma ciência estruturada nos princípios ecológicos e se baseia no manejo de agroecossistemas sustentáveis fundamentados em uma nova teoria da produção com aporte em conhecimento científico. Considera os saberes e práticas tradicionais, abrindo possibilidades de intercâmbios de experiências entre saberes locais e conhecimentos científicos, permitindo a implementação de sistemas de agricultura com finalidades que se coadunam com a preservação da biodiversidade ecológica e da diversidade social e cultural, cujo resultado é a produção de alimentos saudáveis e livres de agrotóxicos.

Uma questão que se coloca é se a agroecologia possui plena capacidade de abastecer a população mundial de alimentos. É dominante a concepção de que é impossível alimentar o mundo (segurança alimentar) sem o agronegócio e o seu regime de plantation usando agrotóxicos, conforme aponta Londres (2011, p. 169).

Embora o discurso predominante da imprensa, da pesquisa agrícola convencional, dos agentes do agronegócio e ate mesmo do governo procure fazer crer que o mundo não é mais capaz de alimentar sua população sem o uso de agrotóxicos, diversas experiências registradas nas mais variadas partes do mundo mostram que a realidade não é bem essa.

Uma equipe de pesquisadores da Universidade de Michigan (Estados Unidos), por exemplo, fez um amplo levantamento de dados documentados em todo o mundo comparando a produtividade de sistemas convencionais, agroecológicos e tradicionais e concluiu que a agricultura agroecológica pode sim abastecer toda a população mundial, tanto local como globalmente. ${ }^{2}$

No cenário de crise, que é também ecológica, a agroecologia constitui uma alternativa viável, por ser uma prática mais benéfica tanto para a natureza, como para os seres humanos (trabalhadores, agricultores e consumidores), com a possibilidade de produção de alimentos saudáveis. Dessa forma, se coloca a necessária conscientização sobre a preservação ambiental, incumbência do poder público, como preconiza o texto constitucional de 1988. Para esse fim, o conhecimento da normativa sobre a agroecologia, como alternativa viável e capaz de se constituir em prática protetora do meio ambiente, se torna necessário para fundamentar a educação e a conscientização ambientais.

\section{ASPECTOS NORMATIVOS SOBRE A AGROECOLOGIA}

As Constituições anteriores (1824, 1891, 1934, 1937, 1946 e 1967) não abordavam, especificamente, a temática do meio ambiente. É a CF/1988 que apresenta vasta proteção ao meio ambiente, sendo, inclusive, considerada uma "Constituição Verde". Importante registrar que a Carta Magna visa defender o meio ambiente e a qualidade de vida individual e coletiva, no cenário de acentuada crise social e ambiental (BENJAMIN, 2007, p.67). Conforme enfatiza Benjamin (2005), superamos o estágio da insuficiência de proteção constitucional relativa ao meio ambiente. Não obstante a existência dessa proteção constitucional, se percebe a necessária promoção, por parte do poder público, da conscientização ambiental, por intermédio da educação.

\footnotetext{
${ }^{2}$ Referência citada no texto original: Badgley, C. et al. (2007). Organic agriculture and the global food supply. Renewable Agriculture and Food Systems: 22(2); 86-108.
} 
Nesse cenário normativo, a CF/1988, no seu Título VIII, "Da Ordem Social”, são apresentadas normas ambientais esparsas. Notadamente no Capítulo VI - Do Meio Ambiente - no qual se insere o relevante art. 225, que, pelo teor do seu conteúdo, legitima o modo de produção da agroecologia, pois que articulado à proteção do meio ambiente ecologicamente equilibrado.

Ressalta-se que o inciso VI, do art. 225 supracitado, apresenta o dever do Poder Público de promover a educação ambiental, para fins de preservação do meio ambiente. Insere-se, nesse quadro normativo o dever de ensino da agroecologia na educação básica, conforme se infere do texto constitucional.

Entretanto, se ressalta a dificuldade na implementação da proteção do meio ambiente conforme a previsão constitucional. Verifica-se que o ensino de agroecologia, ainda, não é uma realidade na estrutura curricular do ensino fundamental e médio (educação básica). Não se concretiza, portanto, a finalidade da norma constitucional, autorizando a responsabilização do Estado. Nesse sentido, aduz Sarlet (2017, p.63-64):

o Estado Socioambiental de Direito, nesse novo cenário constitucional, tem por missão e dever constitucional atender ao comando normativo emanado do art. 225 da $\mathrm{CF} / 1988$, considerando, inclusive, o extenso rol exemplificativo de deveres de proteção ambiental elencado no seu $\S 1^{\circ}$, sob pena de, não o fazendo, tanto sob a ótica da sua ação quanto da sua omissão, incorrer em práticas inconstitucionais ou antijurídicas autorizadoras da sua responsabilização por danos causados a terceiros - além do dano causado ao meio ambiente em si. Nesse contexto, a $\mathrm{CF} / 88$ delineou a competência administrativa (art.23), em sintonia com os deveres de proteção ambiental, de todos os entes federativos (Municípios, Estados, Distrito Federal e União) na seara ambiental, de modo que incumbe a todos a tarefa - e responsabilidade solidária - de "proteger o meio ambiente e combater a poluição em qualquer de suas formas [...]. A partir de tal entendimento, a não atuação (quando lhe é imposto juridicamente agir) ou atuação insuficiente (de modo a não proteger o direito fundamental de modo adequado e suficiente), no tocante a medidas legislativas e administrativas voltadas ao combate às causas geradoras da degradação do ambiente, pode ensejar, em alguns casos, até mesmo a intervenção e o controle judicial inclusive no tocante as políticas públicas levadas a cabo pelos entes federativos em matéria socioambiental.

Dessa forma, o ensino da agroecologia se insere na normativa constitucional do art. 225, especificamente como um dever do Estado de promover a conscientização pública e a preservação ambiental. A efetivação da preservação ambiental está necessariamente relacionada à formulação de projetos pedagógicos de educação ambiental, com a inclusão da agroecologia, seus princípios e práticas na estrutura curricular. Tendo-se como parâmetro a necessidade de proteção eficaz do meio ambiente, se faz necessário, por intermédio da educação formal, incluir o ensino e o fomento da agroecologia. Por seu próprio conceito, a agroecologia não degrada o meio ambiente, se consubstanciando no modo de produção sustentável e que permite a preservação do meio ambiente ecologicamente equilibrado.

Além da CF/88, a legislação infraconstitucional sobre preservação ambiental legitima a agroecologia, tais como a Lei Federal no 10.831/2003, que operacionaliza legalmente a produção agroecológica, instituindo direitos e deveres. Apresenta definições para diferenciar a agroecologia da produção do agronegócio, como, por exemplo, no seu artigo $1^{\circ}$, e em seus incisos, explicita o modo de produção agroecológico como um sistema caracteristicamente orgânico de produzir, marcado pelo respeito à integridade cultural das comunidades rurais e tradicionais.

Por sua vez, o Decreto Federal $n^{\circ}$ 7.794/2012, que institui a Política Nacional de Agroecologia e Produção Orgânica, regulamenta a Lei Federal n ${ }^{\circ} 10.831 / 2003$, a qual institui a Política Nacional de Agroecologia e Produção Orgânica (PNAPO).

Importante registrar que lacunas na promoção da educação ambiental (art. 225, VI), e a

Revista de Direito Brasileira | Florianópolis, SC | v. 24 | n. 9 | p.365-377 | Set./Dez. 2019 
falta de fomento da agroecologia, também, concorreram para a existência de efetiva "crise ambiental" e de sua falta de conscientização. Essa crise apresenta duas dimensões; (1) ecológica: incompatibilidade entre a manutenção do patrimônio ambiental (ecologicamente equilibrado) e cultural e a necessidade de desenvolvimento; (2) social: formas de exclusão que derivam da concentração da riqueza, dos bens e serviços ambientais por um grupo reduzido de atores econômicos, em que os mais pobres e fracos são penalizados (injustiça ambiental e social), tendo de morar em locais de risco, servir-se de águas e alimentos contaminados" (BOFF, 2003, p.49).

Infere-se que a agroecologia se insere no rol dos deveres constitucionais do poder público. Seu fomento é necessário para concretização do objetivo do meio ambiente ecologicamente equilibrado (art. 225, CF/88). O seu ensino, portanto, se constitui como uma obrigação do Estado (inciso VI, art. 225, CF/88), para fins de preservação da natureza.

\section{ENSINO DE AGROECOLOGIA: PARÂMETROS TEÓRICOS E EPISTEMOLÓGICOS}

Preliminarmente, se faz necessária uma introdução sobre a abordagem da ecologia de saberes como uma proposta teórica e epistemológica a embasar a prática educativa sobre a agroecologia e o seu ensino. O professor Boaventura de Sousa Santos, catedrático da Universidade de Coimbra (Portugal), o qual é uma das referências sobre abordagens teóricas que partem da perspectiva do Sul Global, consiste em um dos proponentes dessa abordagem, a qual ganhou reforço teórico de grupos de pesquisadores oriundos de grupos de investigação da América Latina. No livro A gramática do tempo: para uma nova cultura política, o professor apresenta a proposta da ecologia de saberes a partir da crítica radical da hegemonia do paradigma da ciência moderna ocidental, o qual se constitui como um cânone a dominar as práticas de produção de conhecimento, excluindo e marginalizando conhecimentos e saberes produzidos por grupos subalternos e oprimidos, tais como os saberes dos povos tradicionais da América Latina. O autor chega à conclusão que a luta pela valorização dos saberes e das práticas dos povos excluídos do cânone moderno de fazer ciência se constitui como uma luta contra a exclusão de outros tipos de conhecimentos produzidos pela humanidade, tal como os saberes das comunidades tradicionais indígenas, quilombolas. Consiste, portanto, em uma luta pela concretização da justiça cognitiva.

$\mathrm{O}$ autor explicita a ecologia de saberes como uma proposta epistemológica e de aprendizagem com o Sul Global. Nas palavras de Santos (2007, p. 86).

O contexto cultural em que se situa a ecologia de saberes é ambíguo. Por um lado, a ideia da diversidade sociocultural do mundo se fortaleceu nas três últimas décadas, favorecendo o reconhecimento da pluralidade epistemológica como uma de suas dimensões. Por outro lado, se todas as epistemologias partilham as premissas culturais do seu tempo, uma das mais bem consolidadas premissas do pensamento abissal talvez seja, ainda hoje, a da crença na ciência como única forma de conhecimento válida e rigorosa. Ortega y Gasset propôs uma distinção radical entre crenças e ideias, entendendo por estas últimas a ciência ou a filosofia. A distinção reside em que as crenças fazem parte de nossa identidade e subjetividade, enquanto as ideias nos são exteriores. Enquanto nossas ideias nascem da dúvida e permanecem nela, nossas crenças nascem da ausência de dúvida. No fundo, a distinção é entre ser e ter: somos as nossas crenças, temos ideias. O que é característico do nosso tempo é o fato de a ciência moderna pertencer simultaneamente ao campo das ideias e ao campo das crenças. A crença na ciência excede em muito o que as ideias científicas nos permitem realizar. Assim, a relativa perda de confiança epistemológica na ciência durante a segunda metade do século XX ocorreu de par com a crescente crença popular na ciência. A relação entre crenças e ideias como duas entidades distintas passa a ser uma relação entre duas maneiras de experienciar socialmente a ciência. Essa dualidade 
faz com que o reconhecimento da diversidade cultural do mundo não signifique necessariamente o reconhecimento da diversidade epistemológica do mundo.

Com aporte nessa perspectiva, o ensino de agroecologia pode ser realizado em diálogo com outras formas de produção de conhecimento, tais como as artes, poesia, dança, conhecimento das comunidades tradicionais indígenas, quilombolas, dos pequenos agricultores do sertão do Nordeste brasileiro, que produzem alimentos de forma agroecológica, possuindo técnicas e saberes não registrados em manuais ou reconhecidos cientificamente em sua maior parte, mas que funcionam e têm sustentado seu modo tradicional de vida. A efetivação do ensino da agroecologia, na prática, leva ao conhecimento e conscientização sobre a produção de alimentos livres de agrotóxicos, não prejudiciais ao meio ambiente no processo produtivo.

Ademais, o ensino de agroecologia, na perspectiva da ecologia de saberes, pode contribuir para a conscientização e preservação ambientais. A educação, ao promover o conhecimento sobre a prática agroecológica, com aporte no conhecimento crítico sobre a temática, sem excluir as práticas sustentáveis levadas a cabo por diferentes grupos e comunidades, cumpre o objetivo constitucional de formação para o exercício da cidadania, conforme disposto no art. 205, caput $(\mathrm{CF} / 88)$.

Outra proposta educativa elucidativa para o ensino de agroecologia consiste na prática da investigação temática. Sobre essa metodologia, é possível dialogar com Freire (1987), ao explicitar que a investigação temática constitui um processo contínuo de busca e conhecimento, de criação, centrada na atuação dos sujeitos da aprendizagem, em seu processo de descoberta. Nesse processo, a criticidade da investigação dos temas significativos é essencial à aprendizagem e os temas devem ser alvo de problematização.

Não restam dúvidas de que a proposta pedagógica para o ensino de agroecologia deve se fundamentar numa visão crítica de educação, para fins de concretizar a formação para a cidadania (art. 205, CF/88). Além disso, a abordagem da ecologia de saberes, ao incluir no seu rol o conhecimento científico sem excluir os saberes e as práticas produzidos pelas comunidades tradicionais, contribui para a efetivação do disposto no art. 225 do texto constitucional referente à necessidade de conscientização e preservação ambientais.

A agroecologia tem sido disponibilizada nos cursos de ciências agrárias de nível superior e técnico, formando profissionais que podem exercer várias funções no mercado de trabalho, tais como assessores técnicos, educadores, extensionistas rurais e pesquisadores, junto a comunidades de agricultores de base familiar, bem como empresas que desejam produzir de forma agroecológica. Devido à critica ao modo de produção agrícola tradicional, universidades e setores da sociedade já se mobilizam, de forma significativa, para mudar o cenário agrícola no Brasil, conforme constatação em artigo publicado na REVISTA AGRICULTURAS (2011), experiências em agroecologia, da professora da Universidade Federal Rural de Pernambuco (UFRPE), Maria Virgínia de Almeida Aguiar (2010, p. 5).

A abordagem da ecologia de saberes pode ser utilizada para o ensino da agroecologia, por constituir, em seu próprio conceito e método, a consideração de outros saberes, como os conhecimentos das comunidades, tendo, inclusive, como base uma concepção holística que incorpore a racionalidade camponesa e as técnicas de manejo tradicionais dos recursos (MOTTA , 2005, p.28).

Como se observa, a abordagem da ecologia de saberes e a agroecologia constituem práticas compatíveis e relacionadas epistemologicamente e metodologicamente. A primeira se refere ao modo de adquirir conhecimento, com respeito aos diversos saberes. A segunda, a forma de produzir considerando os diversos saberes e respeitando a natureza, podendo ser concretizada a aprendizagem crítica da agroecologia. Por essa concepção, se torna eficaz a aprendizagem com a utilização de outros saberes, contribuindo na fixação do conhecimento e na reflexão crítica; democratiza o acesso ao conhecimento, ao introduzir novos prismas epistemológicos, tais como o 
conhecimento das comunidades tradicionais indígenas, ou dos agricultores do sertão nordestino, desmistificando e valorizando esses saberes, igualmente válidos, sobre práticas social e economicamente sustentáveis; contribui na formação do cidadão, critico/consciente social, econômico e ambiental, e que preserva o meio ambiente, bem como se alimenta de forma saudável, ante o conhecimento adquirido e a forma de sua aquisição.

Com a aprendizagem da agroecologia, são tematizados aspectos sociais, econômicos e ambientais relacionados ao meio ambiente, pois o desenvolvimento tecnológico e industrial ameaça a segurança e a qualidade de vida humana e a ciência não consegue prever as consequências (LEFF, 2002, SANTOS, 2001). Danos ambientais são de difícil ou improvável reparação, causando prejuízo à sadia qualidade de vida, à dignidade e à saúde do ser humano, da flora e da fauna. A melhor estratégia para proteger o meio ambiente ainda é a prevenção, evitando que os danos ocorram.

Considerando, ainda, que os riscos e danos ambientais são distribuídos de forma socialmente desigual no espaço (e no tempo, pois as futuras gerações sofrerão as consequências da degradação ambiental, de fato), mas em relação ao espaço físico, constata-se que os mais prejudicados (sentem/sofrem os riscos e consequências) são exatamente os que menos se beneficiam com a degradação ambiental, porque fazem parte da periferia econômica e social, em notória contradição de custo/benefício (BECK, 2001).

Por essas razões e com fundamento no projeto constitucional de proteção e preservação do meio ambiente, se verifica a necessidade do ensino de agroecologia. Com aporte numa perspectiva humanizada, democrática, plural, holística, pedagógica e crítica, proposta da ecologia dos saberes, pode ser efetivado o objetivo de ensinar os alunos do ensino fundamental e médio (educação básica), na perspectiva da conscientização crítica e para o exercício da cidadania sustentável, contribuindo para a preservação do meio ambiente ecologicamente equilibrado e a promoção da segurança alimentar.

\section{CONCLUSÃO}

No presente estudo, o ensino de agroecologia constitui a concretização do imperativo constitucional inscrito no art. 225. A educação e a conscientização ambientais consistem em deveres constitucionais do Poder Público, devendo o ensino de agroecologia se constituir em conteúdo, de forma transversal, a ser vivenciado nas escolas de educação básica (ensino fundamental e médio).

A opção pela agroecologia decorre do fato de apresentar um potencial de modificar a situação agrária e ambiental, com possibilidades de concretização da justiça ambiental e social no campo, contribuindo na resolução dos problemas relacionados à crise da produção agrícola, insustentável em prejuízo da natureza (flora/fauna) e do meio ambiente ecologicamente equilibrado. Dessa forma, contribui para superar, de fato, o paradigma antropocêntrico que considera a natureza como mercadoria ou insumo produtivo.

No ensino de agroecologia, se rompe com o aspecto meramente economicista (natureza como matéria-prima), para fomentar a sustentabilidade na produção, a valorização de saberes agrícolas das comunidades indígenas, quilombolas e tradicionais, além do científico. Favorece a difusão de conhecimentos de fontes plurais que, juntos, contribuem para uma agricultura/alimentação saudável, sem agrotóxicos, com respeito à natureza e ao ser humano (trabalhador rural/consumidores), e à legislação protetiva do meio ambiente.

Considera-se que a crise ambiental não se limita a uma questão técnica, pois se articula a questões sociais, modelos de produção econômicos, práticas discursivas e epistemológicas (ALLEGRETTI; BARCA; CENTEMERI, 2013). Nesse âmbito, se faz necessário repensar a forma de produção dominante, sob pena de inviabilizar a vida e violar direitos da natureza. 
Ademais, a crise atual desafia os limites das formas de conhecimento e de representação deste mundo. $\mathrm{O}$ ensino de agroecologia, com aporte na pedagogia da ecologia de saberes, em face da perspectiva epistemológica do modo de produção industrial do agronegócio, prevalecente na sociedade, o qual considera a natureza como um insumo agrícola, matéria-prima, vai ao encontro de uma perspectiva ecológica ou biocêntrica.

Assim, o desenvolvimento sustentável efetivo exige uma conduta ética no sentido de realizar a produção agrícola respeitando o meio ambiente, superando o paradigma antropocêntrico, nas bases desse modo de produção. Do contrário, em nome do desenvolvimento, se segue impulsionando modelos de produção e de consumo claramente não sustentáveis nem generalizáveis, e que geram uma massa de excluídos de alimentos básicos e de deslocados ambientais, com o simples objetivo de satisfazer os consumos energéticos de uma porção cada vez mais reduzida e seleta da população mundial.

Nesse cenário, o ensino de agroecologia constitui uma prática eficiente de conscientização da geração atual pela educação, ante a necessidade e urgência da ampliação desse modo de produzir que respeita o meio ambiente. Trata-se de uma proposta de produção humanizada e ecológica em benefício recíproco da sociedade e da natureza.

\section{REFERÊNCIAS}

ACSELRAD, H. Ambientalização das lutas sociais: o caso do movimento por justiça ambiental. Estudos Avançados, São Paulo, v. 24, n. 68, p. 103-119, 2010.

. Justiça ambiental: ação coletiva e estratégias argumentativas. In: ACSELRAD, Henri; HERCULANO, Selene; PÁDUA, José Augusto (Org.). Justiça ambiental e cidadania. Rio de Janeiro: Relume Dumará; Fundação Ford, 2004.

Justiça ambiental: novas articulações entre meio ambiente e democracia. Rio de Janeiro: Ibase, 2000.

ALLEGRETTI, G; BARCA, S; CENTEMERI, L. Crise ecológica e novos desafios para a democracia. Revista Crítica de Ciências Sociais, n. 100, p. 5-10, 2013.

ALVARENGA, L.J. $\mathrm{O}$ aspecto imaterial e a transindividualidade do direito a um meio ambiente dignificante, como justificativas teóricas para o reconhecimento do dano ambiental coletivo extrapatrimonial. In: BENJAMIN, Antonio Herman; LECEY, Eladio; CAPPELLI, Sílvia (Org.). MEIO AMBIENTE E ACESSO À JUSTIÇA: FLORA, RESERVA LEGAL e APP; CONGRESSO INTERNACIONAL DE DIREITO AMBIENTAL, 11., 2007, São Paulo. Anais..., São Paulo: Imprensa Oficial do Estado de São Paulo, 2007. v. 2. p. 423-431.

AMBROGI, C; CABRAL, X. A monocultura avança sobre a floresta. Le Monde Diplomatique (Brasil). Cad. Da América Latina XI, p. 12-13, jul. 2009.

ANTUNES, P. B. Direito Ambiental. 7. ed. Rio de Janeiro: Lumen Júris, 2004.

BARROSO, L. R. Interpretação e aplicação da Constituição: fundamentos de uma dogmática constitucional transformadora. 5. ed., rev., atual. e ampl. São Paulo: Saraiva, 2003.

BAUMAN, Z; BORDONI, C. Estado de crise. Tradução de Renato Aguiar. Rio de Janeiro: Zahar, 2016. 191p 
BECK, U. A reinvenção da política. In: GIDDENS, Anthony; BECK, Ulrich; LASH, Scott. Modernização reflexiva: política, tradição e estética na ordem social moderna. São Paulo: Unesp, 1997.

BENJAMIN, A. H. O meio ambiente na Constituição Federal de 1988. In: KISHI, Sandra A. S., et al. Desafios do Direito Ambiental no Século XXI. São Paulo: Malheiros, 2005

Constitucionalização do ambiente e ecologização da Constituição brasileira. In: CANOTILHO, José Joaquim Gomes; LEITE, José Rubens Morato (Org.). Direito constitucional ambiental brasileiro. São Paulo: Saraiva, 2007.

O estado teatral e a implementação do Direito Ambiental. In: BENJAMIN, Antonio Herman (Org.). Direito, água e vida. In: CONGRESSO INTERNACIONAL DE DIREITO AMBIENTAL, 7., 2003, São Paulo. Anais..., São Paulo: Imprensa Oficial do Estado de São Paulo, 2003. v. 1. p. 335-366.

BOBBIO, N. Estado, governo e sociedade: para uma teoria geral da política. Trad. de Marco Aurélio Nogueira. 7. ed. Rio de Janeiro: Paz e Terra, 1999.

A era dos direitos. Tradução Carlos Nelson Coutinho; apresentação de Celso Lafer. Nova ed. - Rio de Janeiro: Elsevier, 2004. - $7^{\text {a }}$ reimpressão.

BOFF, L. Ética \& eco-espiritualidade. Campinas: Verus, 2003.

BORGES, M. C. A. A educação como um direito fundamental, um bem público e um serviço comercializável. Campina Grande: EDUEPB, 2018.

. Princípios Norteadores da Educação em Direitos Humanos na Instituição Universitária. Verba Juris ano 7, nº. 7, jan./dez. 2008 - ISSN 1678-183X.

Bases teórico-metodológicas de uma educação em direitos humanos crítica: problematizando uma concepção libertadora com e a partir de Paulo Freire. In: SANTOS, Boaventura de Sousa \& CUNHA, Teresa (eds.). Direitos humanos e outras gramáticas de dignidade humana. V. 4. Coimbra: Centro de Estudos Sociais, 2015.

BOURDIEU, P. O Poder Simbólico. Tradução de Fernando Thomaz. Ed .DIFEL. Rio de Janeiro. 1989. Disponível em < http://lpeqi.quimica.ufg.br/up/426/o/BOURDIEU_Pier re._O_poder_simb \%C3\%B3lico.pdf> Acessado em 10/10/2018.

BORSATTO, S, Agroecologia e sua epistemologia. Interciência [online] 2012, 37 (setembro): [Data da consulta: 3 de outubro de 2018] Disponível em: 〈http://www.redalyc.org/articulo.oa?id=33925502010> ISSN 0378-1844.

BRASIL, Constituição Federal de 1988. Disponível em: http://www.planalto.gov.br/ccivil_03/constituicao/constituicao.htm. Acesso em: 19/10/2018.

Decreto Federal 7.794 de 20/08/2012. Institui a Política Nacional de Agroecologia e Produção Orgânica. Disponível em: http://www.planalto.gov.br/ ccivil_03/_Ato20112014/2012/Decreto/D7794.htm. Acesso em: 26/09/2018 
Lei Federal 10.831 de 23/12/2003. Dispõe sobre a agricultura orgânica e dá outras providências. Disponível em: http://www.planalto.gov.br/ccivil_03/leis /2003/L10.831.htm. Acesso em: 26/09/2018

CAPRA, Fritjof. O ponto de mutação. Trad. de Álvaro Cabral. 25. ed. São Paulo: Cultrix, 2002

CANOTILHO, J. J. G. Privatismo, associacionismo e publicismo no Direito do Ambiente: ou o rio da minha terra e as incertezas do Direito Público. Ambiente e Consumo, Lisboa, Centro de Estudos Jurídicos, 1996, v. I.

CARNEIRO, F. F. (Org.) Dossiê ABRASCO: um alerta sobre os impactos dos agrotóxicos na saúde / Organização de Fernando Ferreira Carneiro, Lia Giraldo da Silva Augusto, Raquel Maria Rigotto, Karen Friedrich e André Campos Búrigo. - Rio de Janeiro: EPSJV; São Paulo: Expressão Popular, 2015. Disponível em <http://www.abrasco.org.br/dossieagrotoxicos/wpcontent/uploads/2013/10/Dossi eAbrasco_2015_web.pdf> Acessado em 09/10/2018.

CARVALHO, H. M. O camponês, guardião da agrobiodiversidade, 2013. Disponível em<http://www.reformaagrariaemdados.org.br/sites/default/files/O \%20campon\%C3\%AAs, \%20guardi\%C3\%A3o\%20da\%20agrobiodiversidade $\% 20-\%$ 20Horacio\%20Martins\%20de\%20Carvalho\%20-\%202013.pdf> Acessado em 11/10/2018.

CAVALET, V. A formação do engenheiro agrônomo em questão: a expectativa de um profissional que atenda as demandas sociais do século XXI. São Paulo: 1997 (Doutorando em Educação) - Universidade de São Paulo.

FARIAS, T., ALVARENGA, L..2014. - "A iniquidade A (in)justiça ambiental e o ideário constitucional de transformação da realidade: o direito em face da iníqua distribuição socioespacial de riscos e danos ecológicos". In. Carlos E. Peralta, Luciano J. Alvarenga e Sergio Augustin (Org.). Direito e justiça ambiental: diálogos interdisciplinares sobre a crise ecológica. Editora EDUS. 2014. Disponível em:

<http://www.terrabrasilis.org.br/ecotecadigital/images/abook/pdf/Dez.14.25.pdf.pdft>. Acessado 24/10/2018.

FERREIRA, H. S. O risco ecológico e o princípio da precaução. In: FERREIRA, Heline Sivini; LEITE, José Rubens Morato (Org.). Estado de direito ambiental: tendências: aspectos constitucionais e diagnósticos. Rio de Janeiro: Forense Universitário, 2004.

FERREIRA, W. Bordieu e a Educação: Concepção Crítica para pensar as desigualdades socioeducacionais no Brasil. E-Mosaicos- Revista Multidisciplinar de Ensino, Pesquisa, Extensão e Cultura do Instituto de Aplicação Fernando Rodrigues da Silveira. V.2. N.3 Junho/2013. Disponível em: http://www.e-publicacoes.uerj.br/index.php/emosaicos/article/view/8846.

FOLGADO, C. A. R., Agrotóxicos e Estado de Exceção: a Suspensão da Legislação de Agrotóxicos em Atenção aos Interesses do Agronegócio. In: Carlos Frederico Marés de Souza Filho; Priscylla Monteiro Joca; Assis da Costa Oliveira; Bruno Alberto Paracampo Miléo; Eduardo Fernandes de Araújo; Erika Macedo Moreira; Mariana Trotta Dallalana Quintans. (Org.). Direitos Territoriais de Povos e Comunidades Tradicionais em Situação de Conflitos Socioambientais. 1ed.Brasília-DF: IPDMS, 2015, v. 1, p. 10-776. 
FREIRE, P. Pedagogia do oprimido, $17^{\text {a }}$ ed. Rio de Janeiro, ed. Paz e Terra. 1987. Disponível em < http://www.dhnet.org.br/direitos/militantes/paulofreire/paulo_freire_peda gogia_do_oprimido.pdf $>$ Acessado em 19/10/2018.

GUERRA, G. A. D.; ANGELO-MENEZES, M. de N. Agricultura familiar na pós-graduação no Brasil e na Universidade Federal do Pará (UFPA). R B P G, Brasília, v. 4,n. 7, p. 66-86, julho de 2007. Disponível em < http://ojs.rbpg.capes.gov.br/index.php/rbpg/article/view/120/114> Acessado em 19/10/2018.

KUHN, T. S. A estrutura das revoluções científicas. Tradução: Beatriz Vianna Beira e Nelson Boeira. 12.ed. São Paulo: Perspectiva, 2013

LEFF, E. Epistemologia ambiental. Trad. de Sandra Valenzuela; revisão técnica Paulo Freire Vieira. 2. ed. São Paulo: Cortez, 2002.

LEITE, J. R. M. Dano ambiental: do individual ao coletivo extrapatrimonial. 2. ed. São Paulo: Revista dos Tribunais, 2003.

Sociedade de risco e Estado. In: CANOTILHO, José Joaquim Gomes; LEITE, José Rubens Morato (Org.). Direito constitucional ambiental brasileiro. São Paulo: Saraiva, 2007.

LIMA, M. L. M. As limitações do licenciamento ambiental como instrumento da gestão de riscos: considerações à luz da teoria social de Ulrich Beck. In: BENJAMIN, Antônio Herman (Org.). Paisagem, natureza e direito. São Paulo: Imprensa Oficial, 2005. v. 2.

LONDRES, F. Agrotóxicos no Brasil: um guia para ação em defesa da vida. Rio de Janeiro: Ed. AS-PTA- Assessoria e Serviços a projetos em agricultura alternativa, 2011. Disponível em <http://www4.planalto.gov.br/consea/biblioteca/docu mentos/agrotoxicos-no-brasil.-um-guiapara-acao-em-defesa-da-vida $>$ Acessado em 10/10/2018.

MACHADO, P. A. L. M. Direito Ambiental brasileiro. 25. ed. São Paulo: Malheiros, 2017.

MENEGAT, E. Crise urbana na atualidade: indagações a partir do fenômeno da concentração espacial dos pobres em assentamentos ilegais. Le Monde Diplomatique (Brasil): Cad. Da América Latina XI, jul. 2009

MIAILLE, M. Introdução crítica ao Direito. 3. ed. Lisboa: Estampa, 2005.

MOTA, M (org.). Dicionário da Terra. Rio de Janeiro: Editora Civilização Brasileira, 2010.

ONU. Organização das Nações Unidas (Brasil). Declaração da Conferência das Nações Unidas sobre o Meio Ambiente Humano, 1972. Disponível em:

https://www.apambiente.pt/_zdata/Politicas/DesenvolvimentoSustentavel/1972_Declaracao_Esto colmo.pdf . Acesso em: 10/10/2018.

em:

. Declaração do Rio sobre Meio Ambiente e Desenvolvimento, 1992. Disponível 
http://www.meioambiente.pr.gov.br/arquivos/File/agenda21/Declaracao_Rio_Meio_Ambiente_D esenvolvimento.pdf Acesso em: 13/10/2018.

REVISTA AGRICULTURAS: experiências em agroecologia é uma publicação da ASPTA Agricultura Familiar e Agroecologia -, em parceria com a Fundação Ileia - Centre of Information on Low External Input and Sustainable Agriculture. 2011. Disponível em < http://aspta.org.br/revista/v7-n4-ensino-da-agroecologia/>. Acessado em 17/10/2018.

SANTOS, B. S. A gramática do tempo: para uma nova cultura política. $3^{\text {a }}$.ed. São Paulo: Cortez, 2010.

Para além do Pensamento Abissal: Das linhas globais a uma ecologia de saberes. Novos Estudos no 79. Nov. 2007. Disponível em: http://www.scielo.br/pdf/nec/n79/04.pdf . Acesso em: 31/07/2018.

\& MENESES, Maria Paula (orgs.). Epistemologias do Sul. São Paulo: Cortez, 2010. (Introdução; Parte I, 1. Para além do pensamento abissal: das linhas globais a uma ecologia de saberes).

SARLET, I. W., Direito Constitucional Ambiental - 5a ed. rev., atual. e ampl. - São Paulo: Editora Revista dos Tribunais, 2017.

A Eficácia dos Direitos Fundamentais. Porto Alegre: Livraria dos Advogados, 1998. p. 47; OLIVEIRA JÚNIOR, José A. de. Teoria Jurídica e Novos Direitos. Rio de Janeiro: Lumen Juris, 2000. p. 83-96.

SOUZA, J.G.; CABERO DIEGUES, V. Por uma desglobalização da produção alimentar: commodização da agricultura e diversidade produtiva - uma análise de Espanha. GEOgraphia (UFF), v. 14, p. 63-81, 2012.

SOUZA, J. G. A questão indígena: acumulação por espoliação e monopolização do território (a economia política do agronegócio. Revista Prima Facie, João Pessoa- CCJ-PPGCJ-UFPB, V.12, N.22, ANO 12, JAN-JUN, 2013, p.1-42. Disponível em <http://www.periodicos.ufpb.br/ojs2/index.php/primafacie/article/view/19136/10599>. Acessado 24/09/2018.

VITTI, G. S.; SOUZA, J. G. Reprimarização da economia e especialização regional produtiva: análise do EDR de Pindamonhangaba (SP). Anais XVII Encontro Nacional de Geógrafos XVII ENG, 2012, Belo Horizonte-MG. XVII Encontro Nacional de Geógrafos - XVII ENG. Belo Horizonte-MG: AGB- Nacional, 2012. v. 1. p. 1-1. 